\title{
COMPARATIVE ADVANTAGE AND COMPETITIVENESS OF EGYPTIAN EXPORTS OF GARLIC
}

(Received: 17.2.2009)

\author{
By \\ W. M. EL-Bolony \\ Agricultural Economics Research Institute, Section of \\ Regional Studies, Agricultural Research Center, Giza
}

\begin{abstract}
This study aimed to identify the comparative advantage, competitiveness and the economic effects of the prudent Egyptian export of garlic crop. Adopted in achieving the objectives of the study on the use of descriptive statistical analysis and some of the measurements, analytical and statistical standards, through the use of arithmetic averages and percentages, and annual growth rates of the variables under study, as well as an estimate of some transections of a matrix of policy analysis during the period (1994-2006) as well as the composite index was estimated account of the competitive and comparative advantage and the calculation of the apparent intensification of labor and the relative proportion of the global market penetration of the crop of garlic during the period (1994-2006). In addition to the estimated partial equilibrium model for this strategically important during the harvest period (1994-2006).

The results of the study on the most important set of facts :

1- Total net revenues in domestic prices per feddan garlic around 3901.83 pounds, down $59.92 \%$ estimated Boukoual of their extreme economic and about 6239.93 pounds during the study period.

2 - Production compared with the provision of hard currency for the garlic harvest is estimated at 1432.67 U.S. \$ during the study period.

3 - Notes Oscillation clear, and the penetration ratio of the composite index of competitive crop of garlic during the period (1994 - 2006) which will adversely affect not only the exports of the crop, but on agricultural exports in general. This indicates the need to move towards a plan for efficient export by the export of the crop of world markets.

4 - Shows that increasing the implicit subsidy total social welfare of garlic about 36 million pounds during the study period.
\end{abstract}

Key words: agricultural economics, exports, garlic

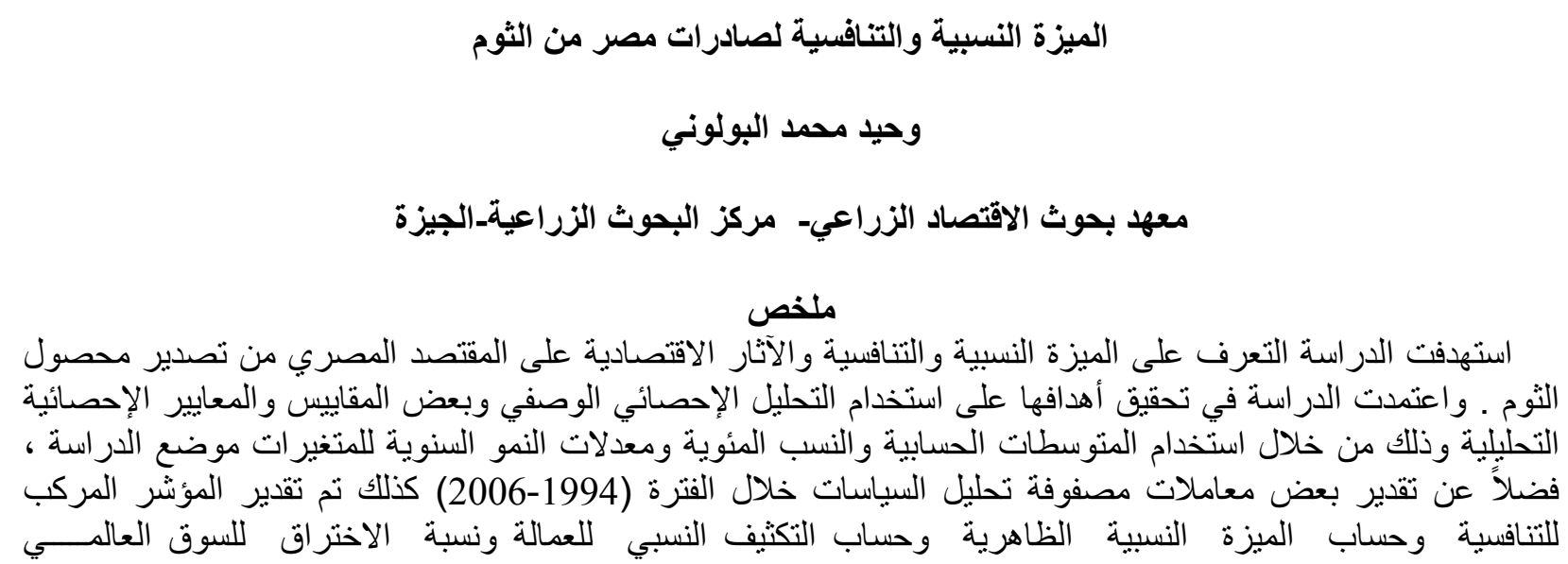


لمحصول الثوم خلال الفترة (1994-2006) ـ بالإضافة إلى تقدير نموذج التوازن الجزئي لهذا المحصول الاستر اتيجي الهام

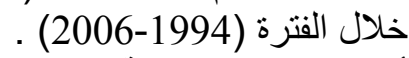

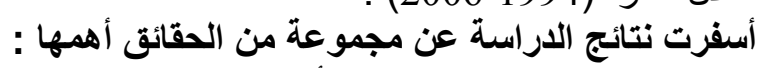

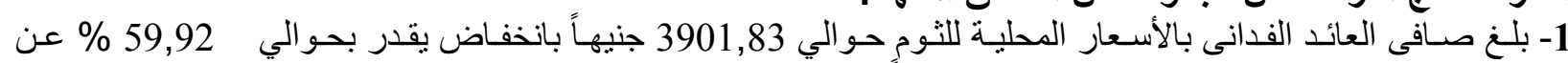

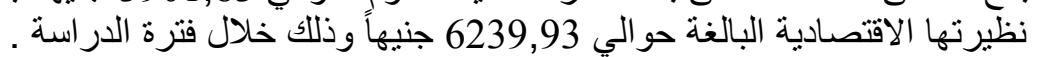

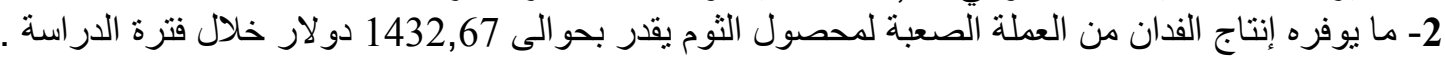

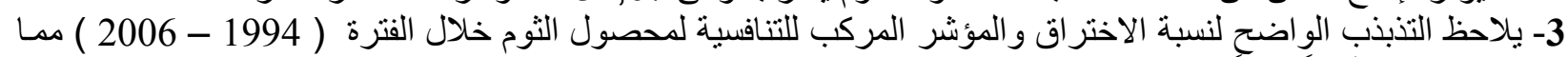

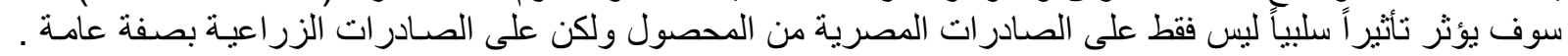

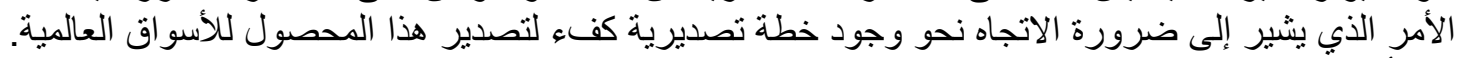

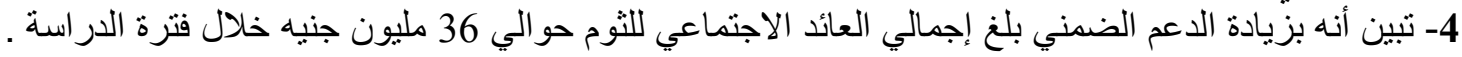

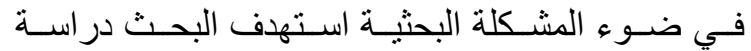

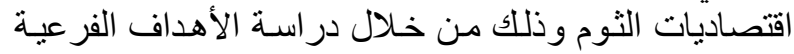

(1 ) الوضع الراهن لمحصول الثوم ( المسـاحة ــ الإنتاجيـة

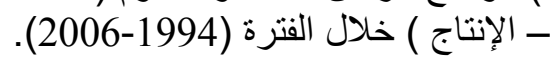

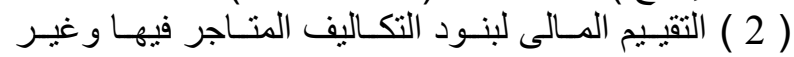

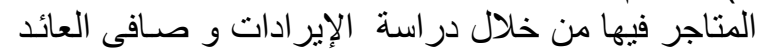

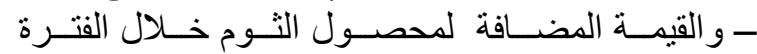

.(2006-1994)

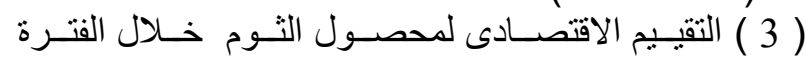
. (2006-1994)

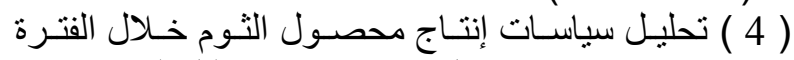
(2006-1994) من خلال تقدير مصفوفة تحليل السياسات. ( 5 ) المؤشر المركب لمحصول الثوم خلال الفترة (1994. 2006

( 6 ) تقدير نمـوذج التوازن الجزئى لمحصـول الثوم خـلال

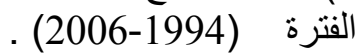

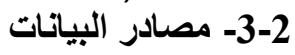

تم الاعتماد على البيانـات الثانويـة المنشـورة مـن الجهاز

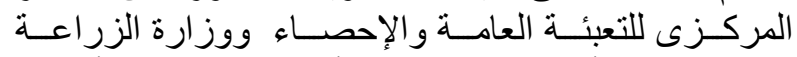

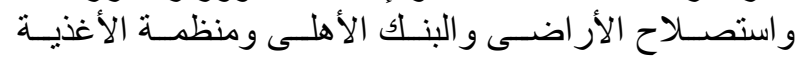

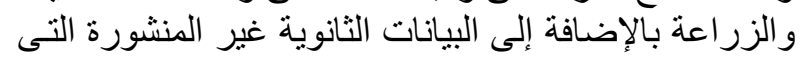

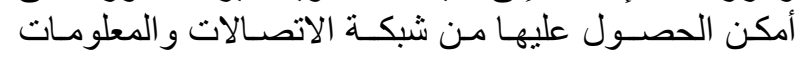

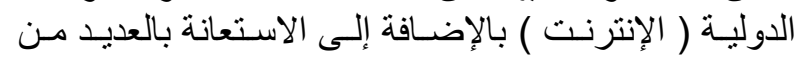

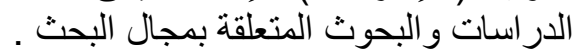

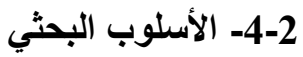

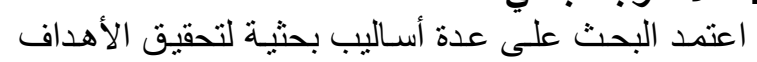

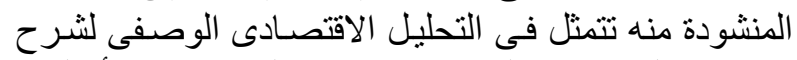

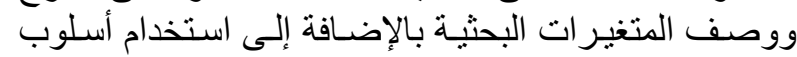

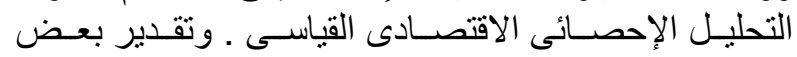
معـاملات مصفوفة تحليل السياسـات التى يمكن مـن خلالها لإنها

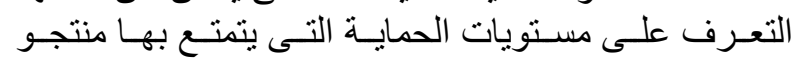

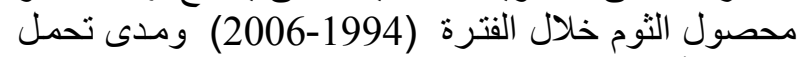

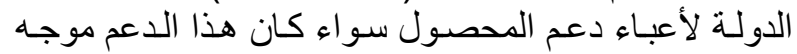

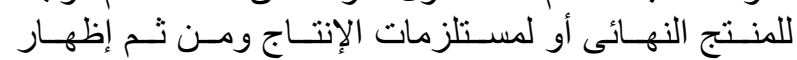

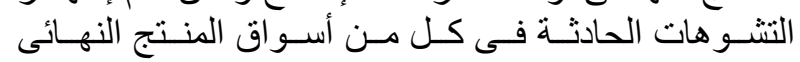

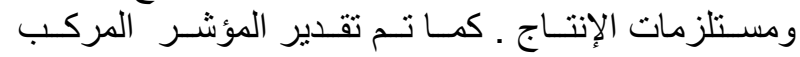

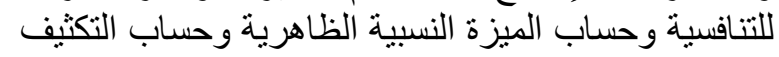

\section{- 1 - مقدمة}

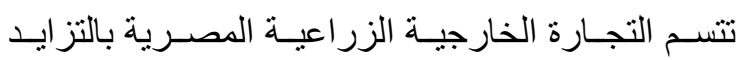

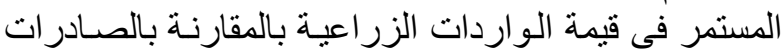

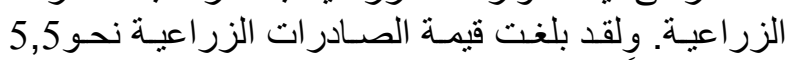

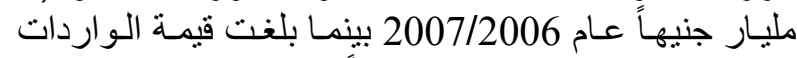

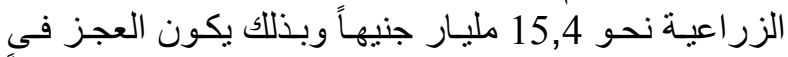

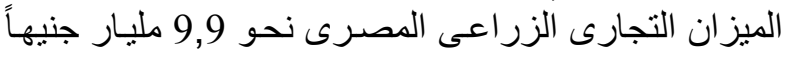
وبنسبة تمثنل نحو 83,0 0/0 مـن العجز العز الكلى البـالغ نحو

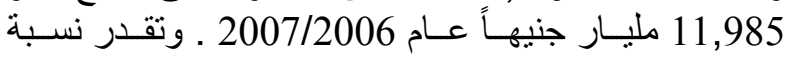

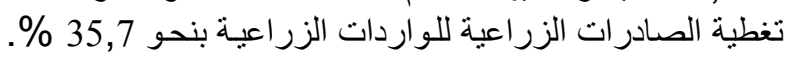

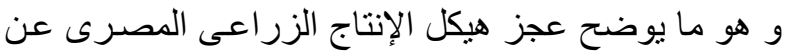

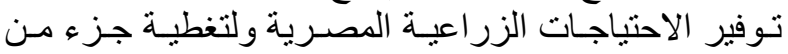

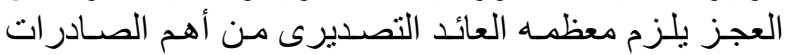

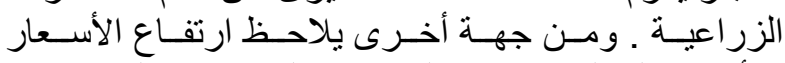

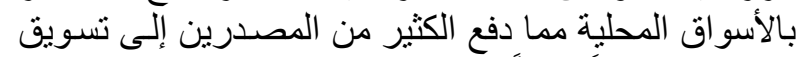

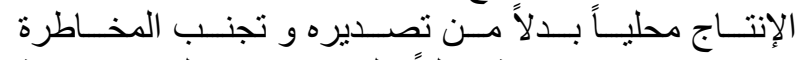
و الإجراءات مما قد يؤثر سلباً على الاقتصـاد القومى بصى بصفة

\section{2.المواد والطرث البحثية} عامة.

\section{1-2 المشكلة البحثية}

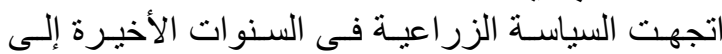

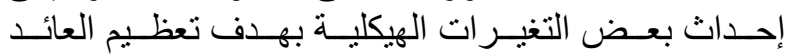

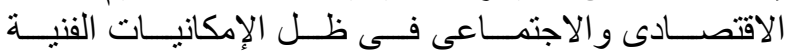

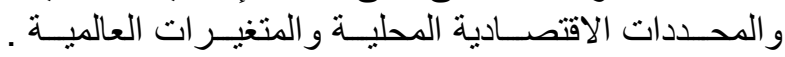

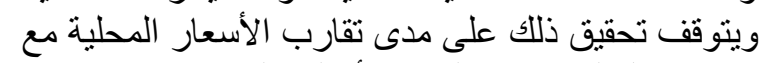

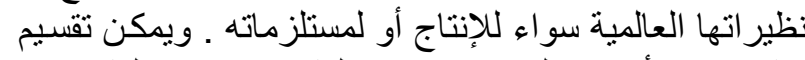

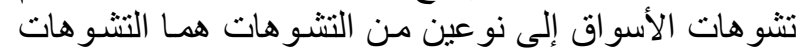

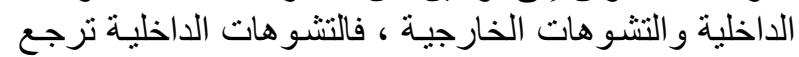

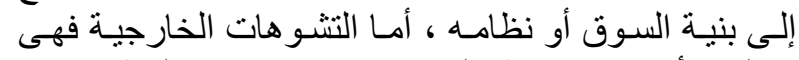

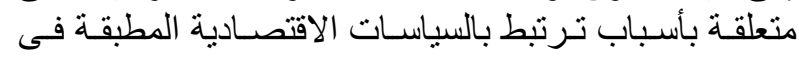

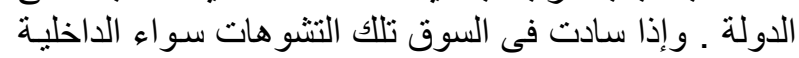

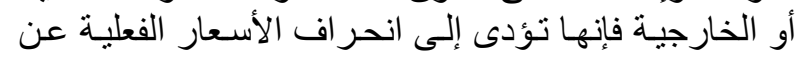

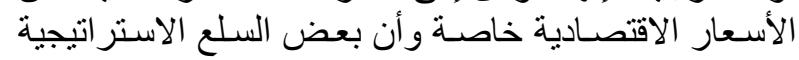

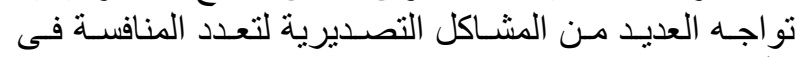
الأسواق العالمية . 2-2-2 الأهداف البحثية البية 
ال2-6-1-2 المفهوم الاقتصـادي لمؤشسرات مصفوفة تحليل السياسات

( ) أ ) معامل الحماية الإسمى للمنتجات(N.P.C.O) Nominal Protection Coefficient of Tradable Output ويقيس هذا المعيار مدى انحر افت الأسعار المحلية الكية

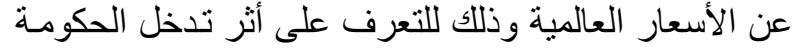

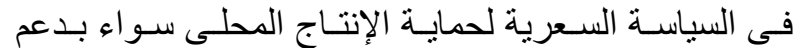

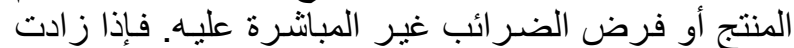

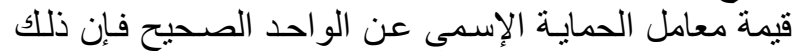

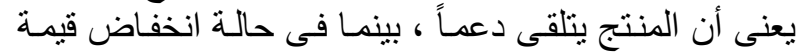

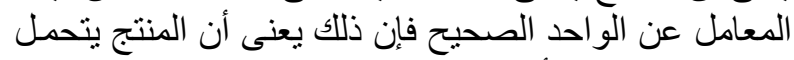

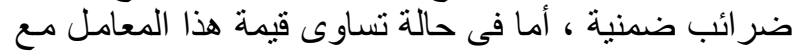
الواحد الصحيح فإن ذلك يدل على وجود سياستة حباديـة

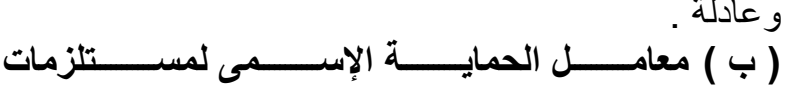
Nominal Protection (N.P.C.I) الإنتاج)

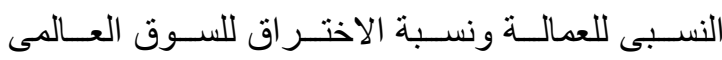

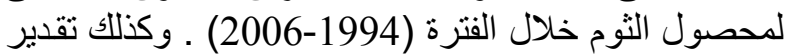

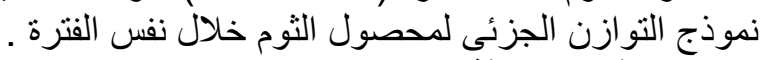
-5-2-2 نموذج مصفوفة تحليل السياسات

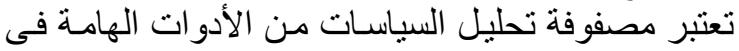

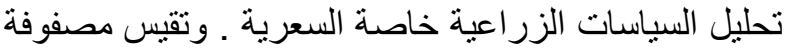
تحليل السياسات التثو هات السعرية الحادثة في اقتصاديات

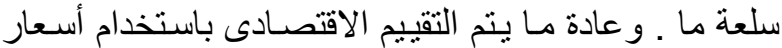
الحدود وتحسب أسعار الحدود للصادرات على النحو التالى لى

سعر الحدود للمحاصيل التصديرية = السعر العالمى سيف بالعملة الأجنيبة للدول المستوردة ـ تكاليف النقل والتنداول

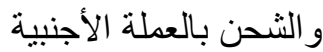

6-2-2 المخطط العام لمصفوفة تحليل السياسات :

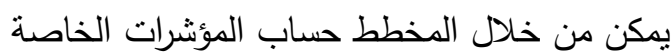
بالسلعة أو المحصول لكل مرحلة من مراحل التحليل.

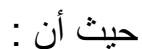
- A

\begin{tabular}{|c|c|c|c|c|c|c|c|}
\hline \multirow{2}{*}{ القضيمة } & \multirow{2}{*}{ صافى العائد } & \multicolumn{3}{|c|}{ تكاليف الموارد المحلية } & \multirow{2}{*}{ مستلزمات الإنتاج } & \multirow{2}{*}{ إجمالى العائد } & \multirow[t]{2}{*}{ البيان } \\
\hline & & إجمالى & الأرض & العمل & & & \\
\hline $\mathrm{G}$ & $\mathrm{F}$ & $\mathrm{E}$ & $\mathrm{D}$ & $\mathrm{C}$ & B & $\mathrm{A}$ & أسعار السوق المحلى \\
\hline $\mathrm{N}$ & $\mathrm{M}$ & $\mathrm{L}$ & $\mathrm{K}$ & $\mathrm{J}$ & I & $\mathrm{H}$ & أسعار الحدود \\
\hline $\mathrm{U}$ & $\mathrm{T}$ & $\mathrm{S}$ & $\mathrm{R}$ & Q & $\mathrm{P}$ & $\mathrm{O}$ & التحويلات \\
\hline
\end{tabular}

Coefficient of Tradable Input

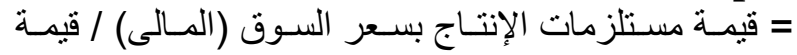
(عتلزمات الإنتاج بسعر الظل (الاقتصادى)

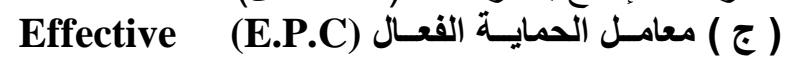
Protection Coefficient

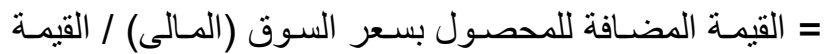

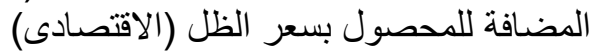

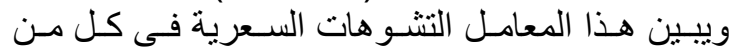

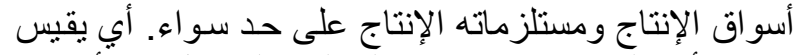

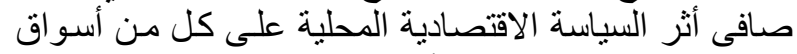

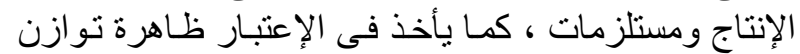

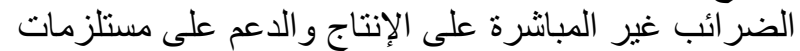

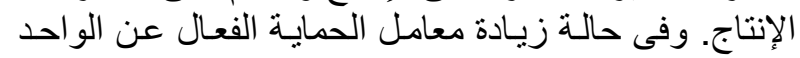

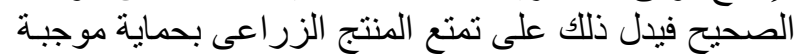

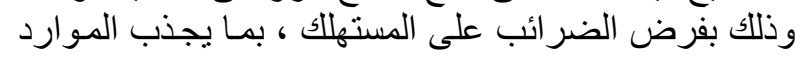

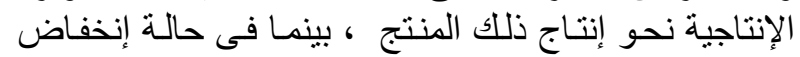

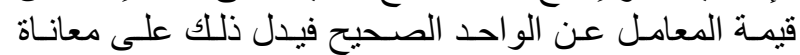

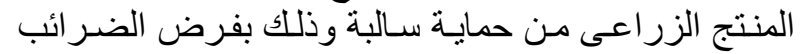

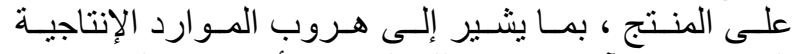

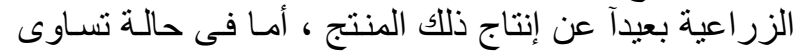

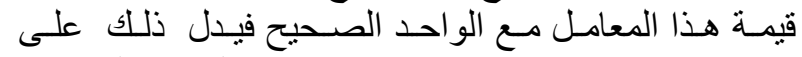

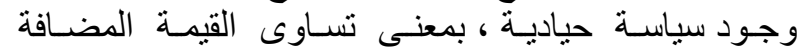

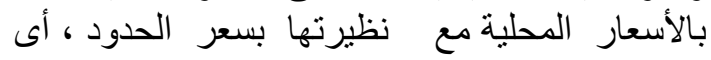

العائد بأسعار الحدود ـ B - قيمة مستلزمات الإنتاج بأسعار

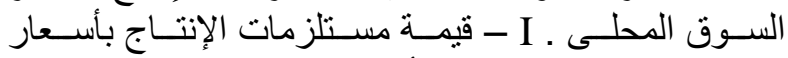

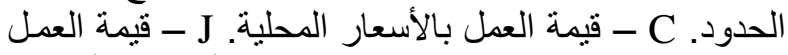

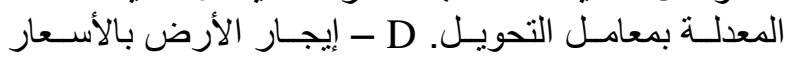
المحلية . K - إيجار الأرض بأسعار الحدود . E - E إلجمالي

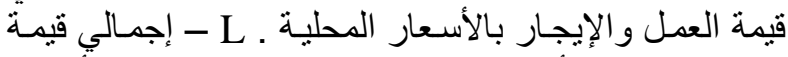

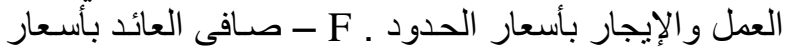

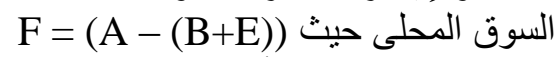
M = (H - صافى العائد بأسعار الحدود حيث - M - G . . (I+L))

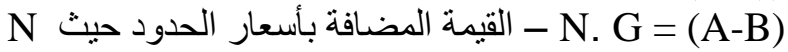
- O. = (H-I) حيث P. O = (A-H) أثر السياسة الزر اعية على أسعار

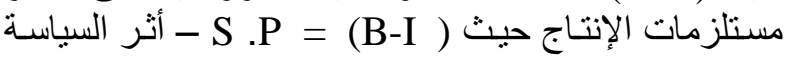

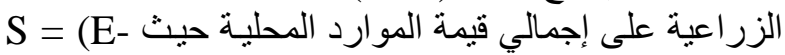
- T . L)

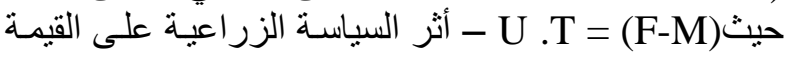
المضافة حيث

مـن خـلال المؤشـرات في مخطط مصفوفة تحليل السياسات يمكن اثتنقاق المعاملات الآتية: 
6- معدل الدعم الحكومى للمنتجين (SRP) : : و يتم حسابه

$$
\text { SRP = }
$$

7- معيـار تكلفـة سياسـة اللـدم (PPC) : : و يـتم حسـابه

$$
\text { عPC }=\frac{D+C}{A-B}=\frac{E}{G} \quad \text { : }
$$

وتعتبـر بنــود تكــاليف الإنتـاج الفدانيــة أحـد العناصـر

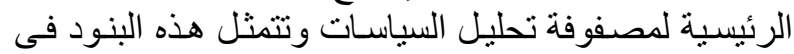

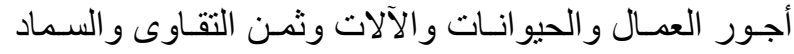

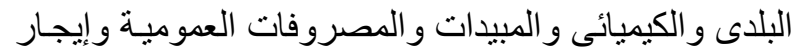

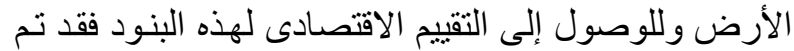

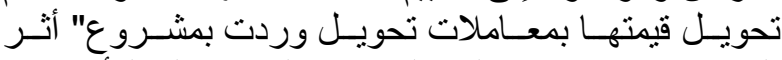

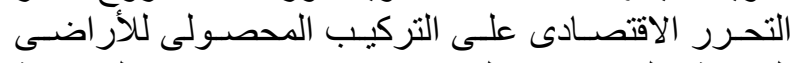

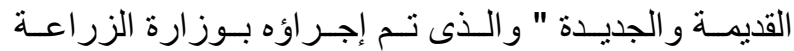

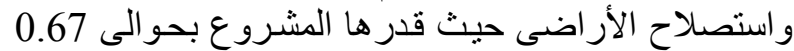

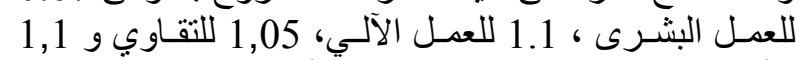

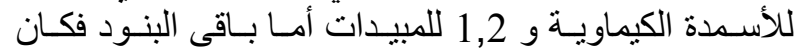

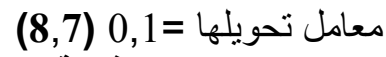

7-2 مؤشرات التنافسية :

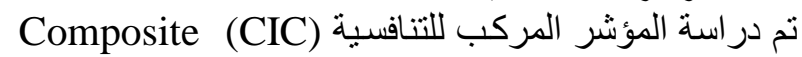
Indicator of Competitiveness

التنافسـية الظاهريــة Composite (RC)

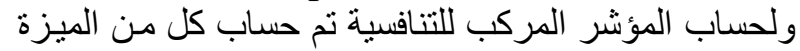
النسبية الظاهرية وحساب التكثيف النسبى للعمالة ثم در استة

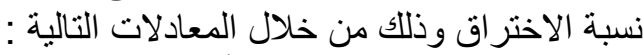
Revealed Comparative Advantage

$\mathrm{RAC}_{\mathrm{E}}=\left(\mathrm{X}_{\mathrm{v}} / \mathrm{X}_{\mathrm{tv}}\right) /\left(\mathrm{X}_{\mathrm{VW}} / \mathrm{X}_{\mathrm{tvW}}\right)$

قيمة الصادر ات المصرية من السلعة إلى العالم بالألف XV دو لار إجمالى قيمة الصادرات المصرية الزراعية إلى X X X العالم بالألف دولار فيمة

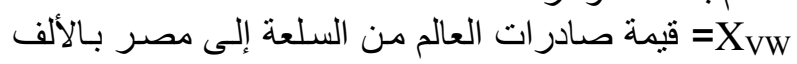

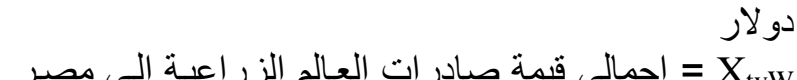
بالألف دو لار

$\mathrm{R}_{\mathrm{E}}=\left(\mathrm{RACE}-\mathrm{RAC}_{\min }\right) /\left(\mathrm{RAC}_{\min }-\mathrm{RAC}_{\max }\right)$ RACE$$
\text { = RAC أدنى مبزة نسبية ظاهرية خلال فترة الدراسة }
$$

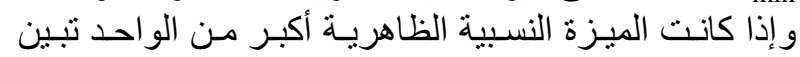

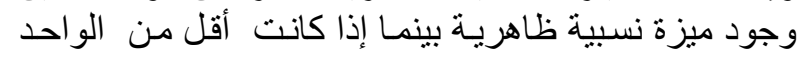

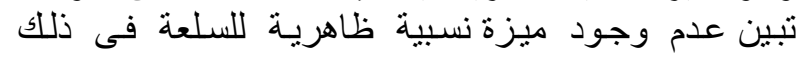
Market Penetration السوق. ( ب ) نسبة اختر اق السوة Ratio

$$
\mathrm{MPR}_{\mathrm{E}}=\mathrm{M}_{\mathrm{W}} /\left(\mathrm{Q}_{\mathrm{W}}+\left(\mathrm{M}_{\mathrm{W}}-\mathrm{X}_{\mathrm{W}}\right)\right.
$$

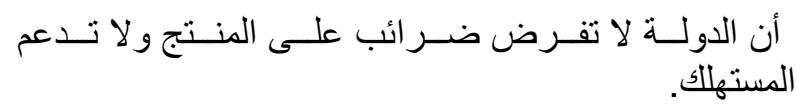

Domestic (D.R.C) (د ) معامل تكلفة الموارد المحلية ) Resource Cost

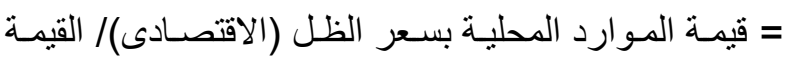

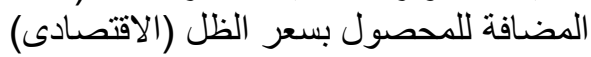

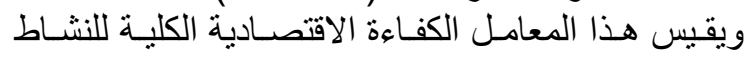

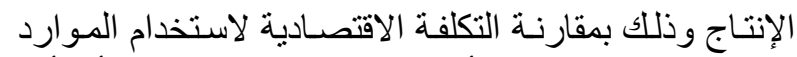

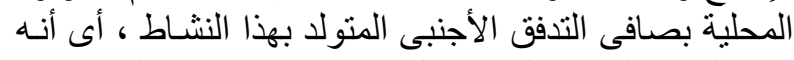

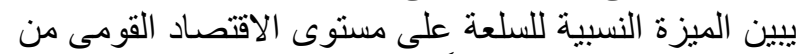

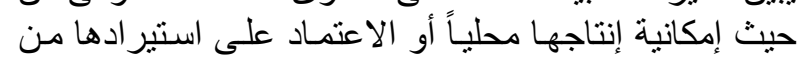

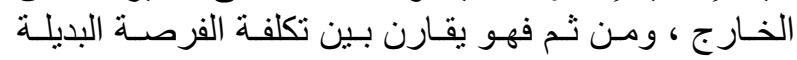

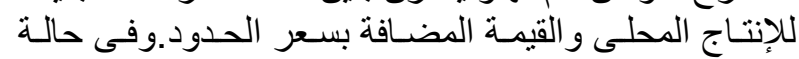

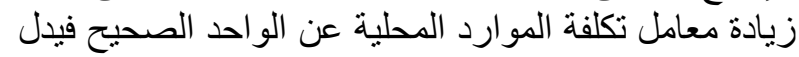

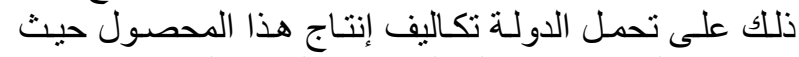

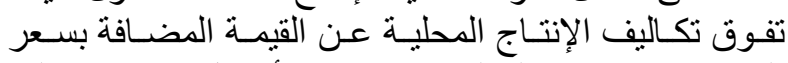

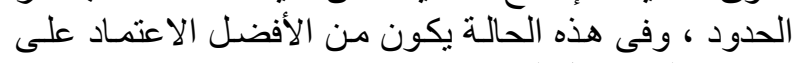

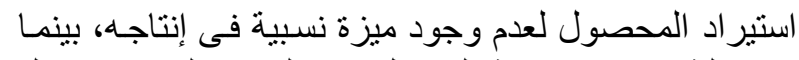

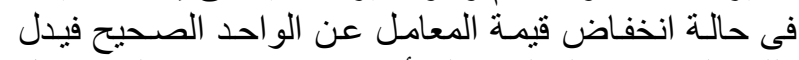

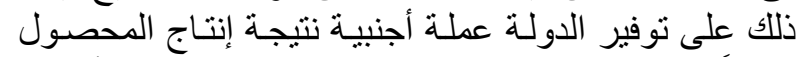

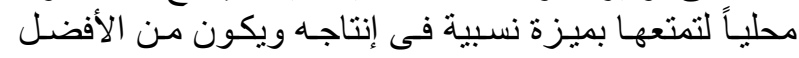

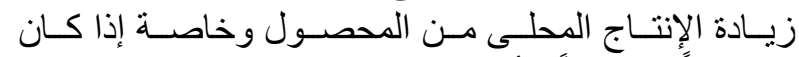

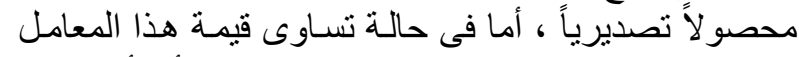

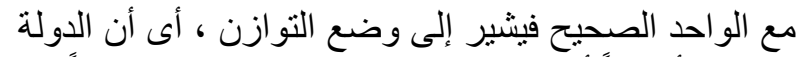

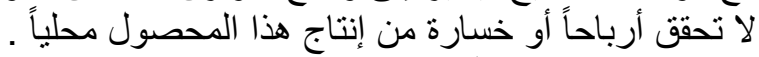

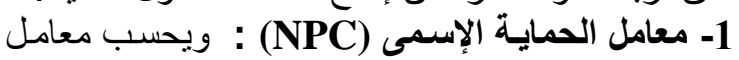

$$
\text { الحماية الإسمى للنواتج }
$$

و يحسب معامـل الحمايـة الإسـى لمستلزمات الإنتـاج

NPCI =

2- معدل الحماية الإسمى (NPR) :

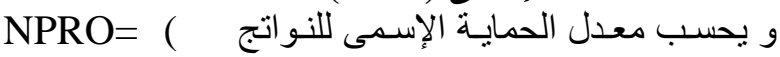
NPCO -1 )*100

و يحسـبـ معـدل الحمايــة الإســمى لمسـتلزمات الإنتــاج

NPRI = ( NPCI -1 )*100

3- معامل الحماية الفعال (EPC) : و يحسب هذا المعامل

$$
\text { كالتالي }
$$

4- معـدل الحمايــة الفعـال(EPR) (EPR) : و يحسـب كالتـالي

$\mathrm{EPR}=(\mathrm{EPC}-1) * 100$

5- معامــل الميـزة النســية أو تكلفــة المــوارد المحليـة

: (DRC)

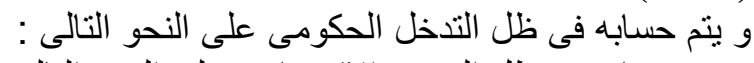

و يتم حسابه فى ظل التحرر الاقتصادى على على النحو التالى لـى

$$
\begin{aligned}
& \frac{C+D}{A-I}=\frac{E}{G} \mathrm{DRC}=: \\
& \frac{J+K}{H-I}=\frac{L}{N} \mathrm{DRC}=
\end{aligned}
$$


كانت سالبة دل ذلك على عدم وجود ميزة لتلك السلعة فىى

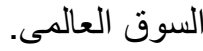

8-2- بعض المفاهيم البحثية لنموذج التوازن الجزئحى :

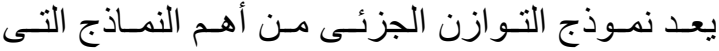

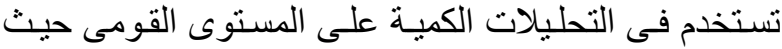

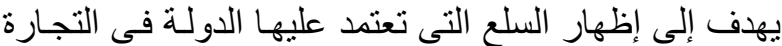

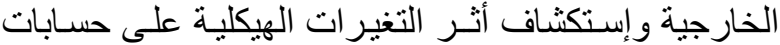

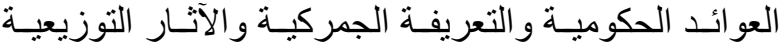
للمنتجين و المستهلكين على المستوى القومى وكذللك التعرف

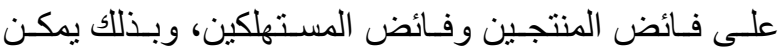

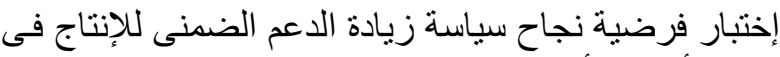

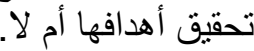

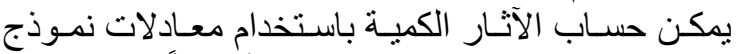

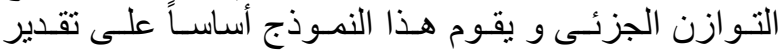

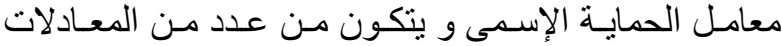
الآتية : معامية 1- التغير في عوائد الحكومة : $\Delta G R=\left\{\frac{1-N P C}{N P C}\right\}(V-W)$

2- صافى الخسارة على مستوى المنتج : $N E L_{P}=0.5 e s\left\{\frac{1-N P C}{N P C}\right\}^{2} V$

4- صافى الخسارة على مستوى المستهلك : NEL ${ }_{c}=0.5 n d\left\{\frac{1-N P C}{N P C}\right\}^{2} W$

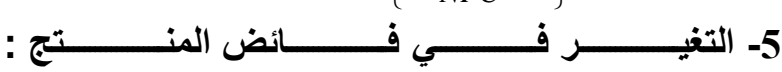

$W G P=-\left\{\left\langle\frac{1-N P C}{N P C} V\right\rangle\right\}+N E L_{P}$

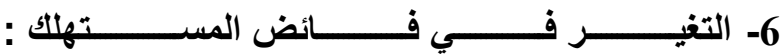
$W G C=\left\{\left\langle\frac{1-N P C}{N P C} W\right\rangle\right\}-N E L_{C}$

: (NEL $\left.{ }_{P}+N E L_{C}\right)$

Net Effect = -

حيث : V = قيمة الإنتاج عند السعر المحلى = W = NPC = Es Nd

\section{3-النتائج البحثية والمناقثة}

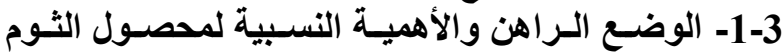
بجمهورية مصر العربية خلال الفترة ( 1994-2006 ) ): 1- المؤشرات الاقتصادية لمحصول الثوم :

يتضح من استعر اض تطور البيانات الواردة بالملحق

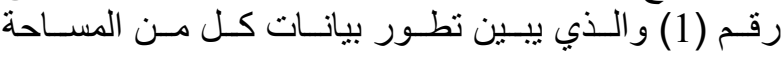

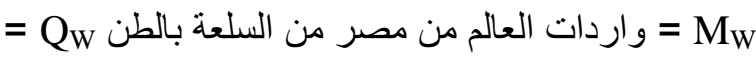
إنتاج العالم من السلعة بالطن

كمية صادر ات العالم من السلعة إلى مصر بالطن $\mathrm{R}_{\mathrm{E} 1}=\left(\mathrm{MPR}_{\mathrm{E}}-\mathrm{MPR}_{\min }\right) /\left(\mathrm{MPR}_{\min }-\right.$ $\left.\mathrm{MPR}_{\max }\right)$ = MPRE E العام E

و = أعلى نسبة اختراق خلال فترة الدراسة.

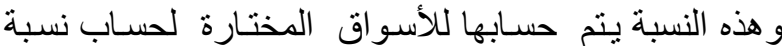

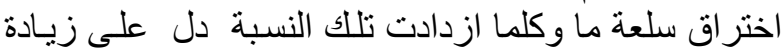

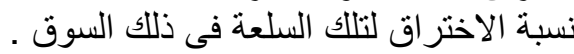

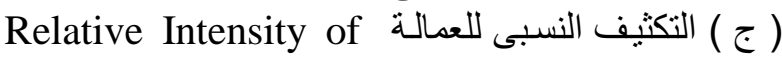
$\mathrm{RIL}_{\mathrm{E}}=(\mathrm{WLE}) /(\mathrm{AVE})$ Labor = أجور العمالة فى إنتاج السلعة . AV = القيمة المضافة للسلعة المصرية المنتجة العماتة المباجة $\mathrm{R}_{\mathrm{E} 2}=\left(\mathrm{RIL}_{\mathrm{E}}-\mathrm{RIL}_{\min }\right) /\left(\mathrm{RIL}_{\max }-\mathrm{RIL}_{\min }\right)$ RIL أدنى تكثيف نسبى للعمالة المنتجة للسلعة خلال فترة الدر اسة.

RIL = أعلى تكثيف نسبى للعمالة المنتجة للسلعة خلال

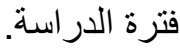

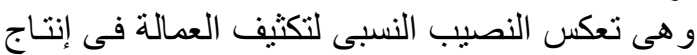

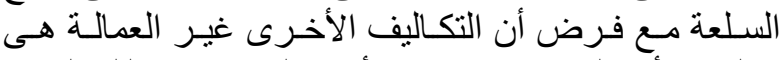

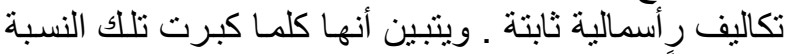

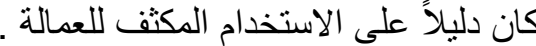

Composite Indicator د المؤشر المركب للتنافسية المكية for Competitiveness

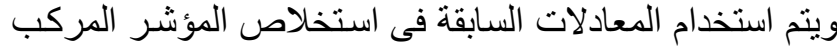

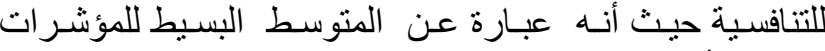
الثناثة الأخيرة $\mathrm{CIC}_{\mathrm{E}}=\left(\mathrm{RE} 1+\mathrm{R}_{\mathrm{E} 2}+\mathrm{R}_{\mathrm{E} 3}\right)$ هام = Re

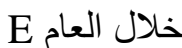

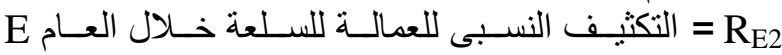

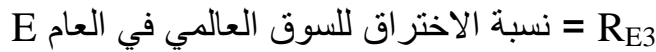

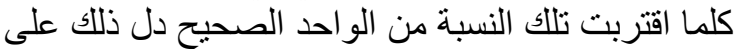

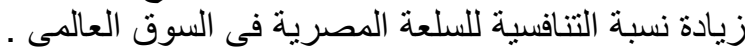

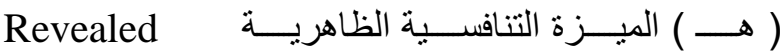
Competitive Advantage $\mathrm{RC}_{\mathrm{E}}=\mathrm{RCA}_{\mathrm{E}}-\left(\left(\left(\mathrm{M}_{\mathrm{E}} / \mathrm{M}_{\mathrm{W}}\right) /\left(\mathrm{MT} / \mathrm{M}_{\mathrm{WT}}\right)\right)^{*}\right.$

RCAE السوق العالمى. = قيمة الواردات الزر اعبة من السلعة من العالم بالألف

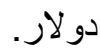
MW

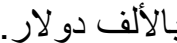
= إجمالى قيمة الواردات الزر اعية المصرية من العـالم

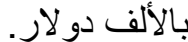

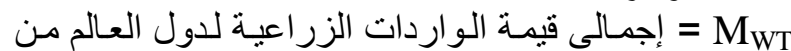
مصر بالألف دولار.

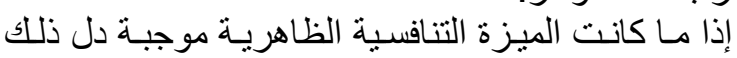

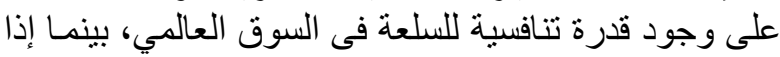




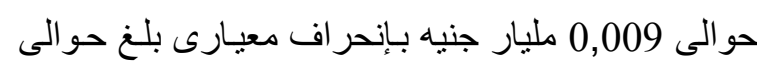
8, 8002 مليار جنيه عن المنوسط . 8- تراوحت نسبة الإكتفاء الذاتى من محصول الثن الثوم بين حد

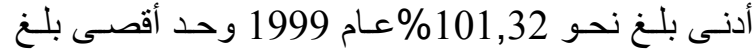

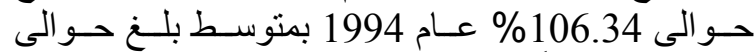

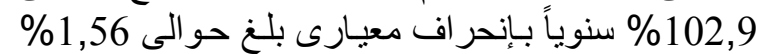
عن المتوسط.

Policy Analysis تقدير مصفوفة تحليل السياسات . Matrix

تم استخدام مصفوفة تحليل السياسات لتقدير معاملات

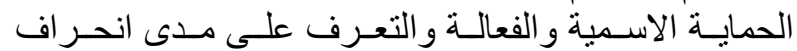

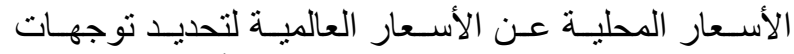

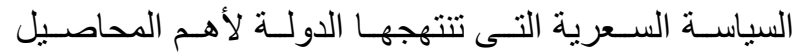
الزر اعية ، وكذللك تقدير معامل تكلفة المو ارد التئ

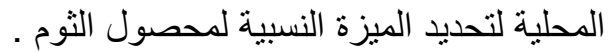

1- يثبير جدول (1) إلى نتائج تقدير مصفوفة تحليل

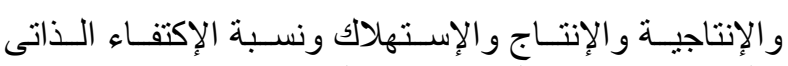
و والصادر ات وقيمة الصادرات وات الات مايلى :

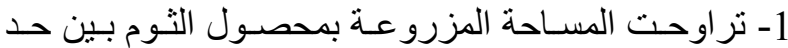
أدنى بلغ حو الى 11,9 ألف فدان عام 1994 وحد القد أقصى

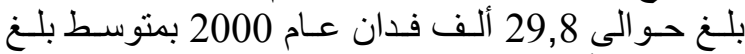

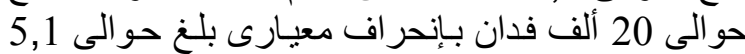
ألف فدان عن المتوسط.

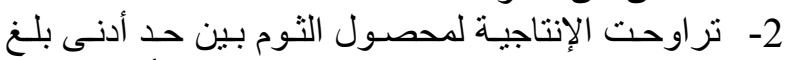

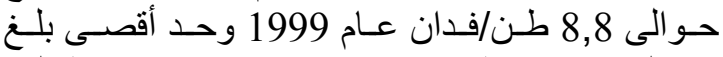

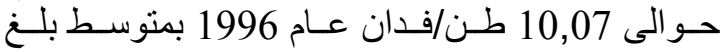

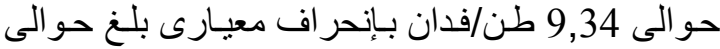
0,39 طن/فدان عن المتوسط.

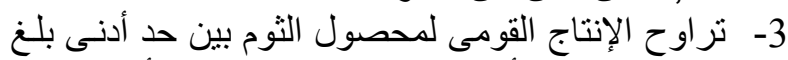

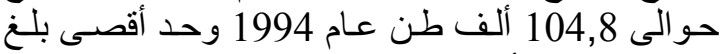

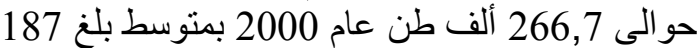
الف طن بـإنحر اف معيارى بلـغ حو الى 48 ألف طن طن عن الف المنوسط.

\begin{tabular}{|c|c|c|c|c|c|c|c|c|}
\hline \multicolumn{9}{|c|}{ جدول رقم ( 1 ): مصفوفة تحليل السياسات لمحصول الثوم خلال الفترة ( 1994-2006) } \\
\hline \multirow{2}{*}{ المضافة } & \multirow{2}{*}{ صافي } & \multicolumn{4}{|c|}{ تكلفة الموارد المحلية } & \multirow{2}{*}{ مستلزمات } & \multirow{2}{*}{ إلجمائدي } & \multirow[b]{2}{*}{ البيـــــان } \\
\hline & & إجمالي & مصروفيةت & 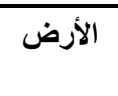 & 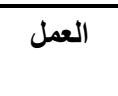 & & & \\
\hline 4629,84 & 3901,83 & 1498,95 & 166,38 & 573,68 & 758,88 & 770,93 & 5400,77 & التقييم المالي \\
\hline 6749,45 & 6239,93 & 1343,07 & 166,38 & 573,68 & 603,00 & 833,55 & 7583,00 & التقييم الاقتصادي \\
\hline $2119,61-$ & $2338,10-$ & 155,88 & 0,00 & 0,00 & 155,88 & $62,62-$ & $2182,23-$ & أثر السياسة \\
\hline
\end{tabular}

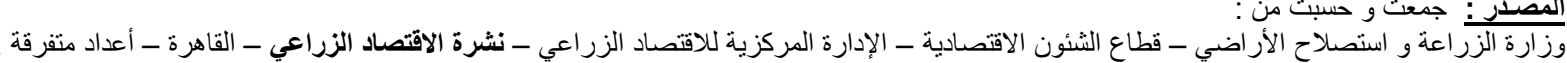

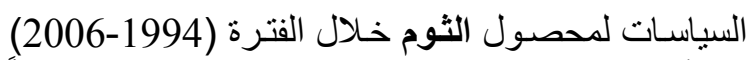

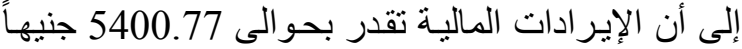

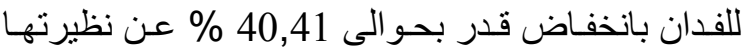

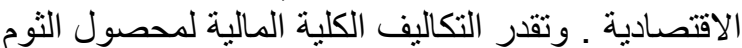

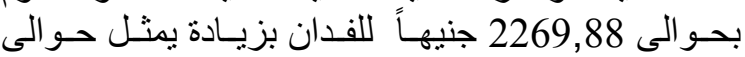

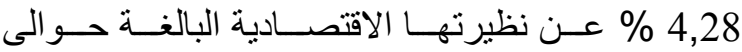

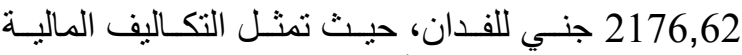

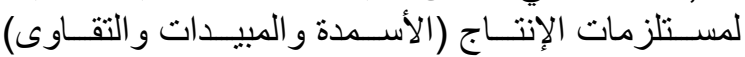

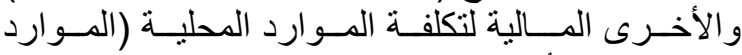

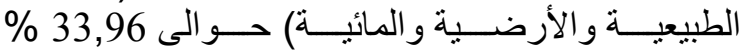
وحو الى 66,04 \% مـن إجمـالى التكـاليف الماليـة ، فـى

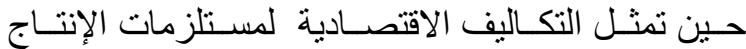

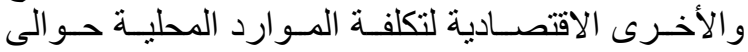

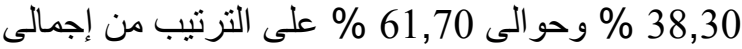

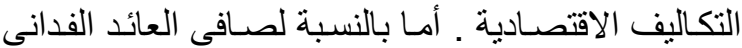

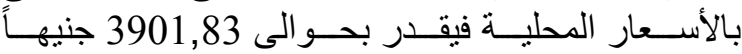

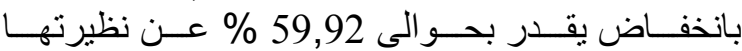
الاقتصادية البالغة حو الى 6239,93 جنيهاً.

(وزارة الزراعة و استصلاح الأر اضي ـ قطاع الثئون

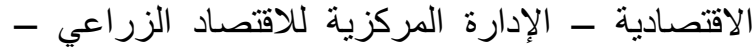

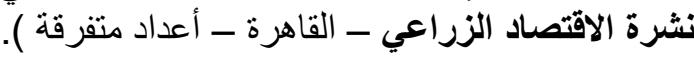

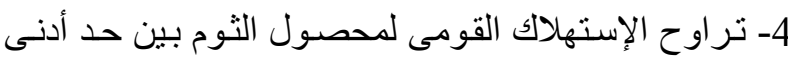

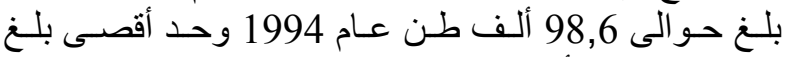

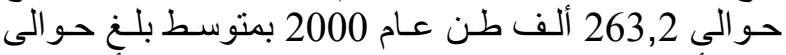
182 ألف طن بإنحر اف معيارى بلـغ حو الى 48 ألَف طن بـن عن المتوسط. 5- نراوحت التكاليف الإنتاجية للفدان لمحصول الثوم بين حد

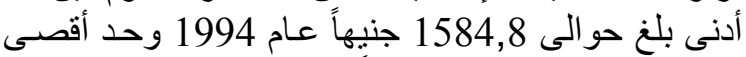

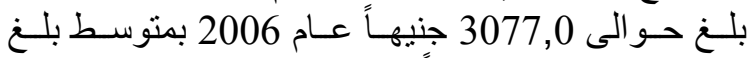

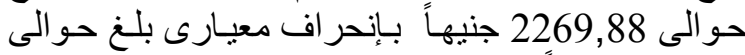
109,11 جنيهاً عن المتوسط ، وقدرت الزيـادة السنوية

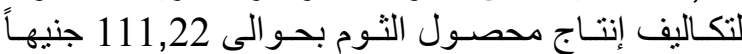

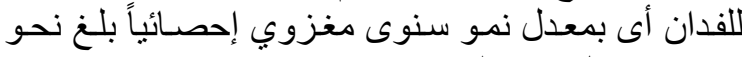

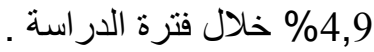
6- تراوحت الصادرات القومية لمحصول الثرة الثوم بين حد أدنى

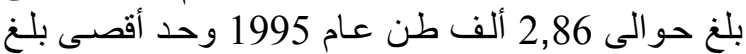

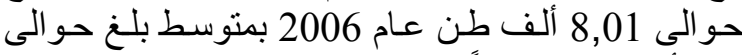

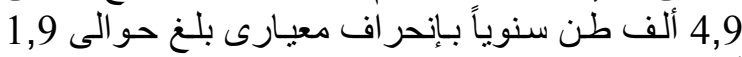
ألف طن عن المتوسط .

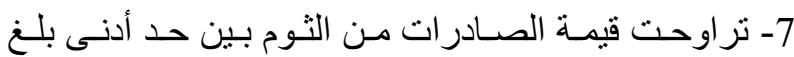

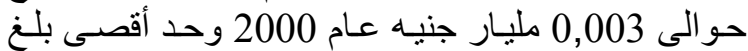

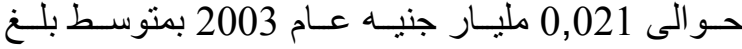




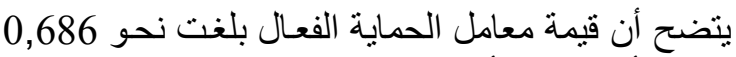
3-3-3 مؤشـرات مصـفوفة تحليـل السياســات لمحصـول

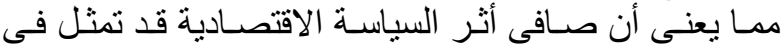

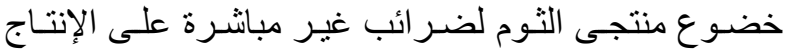

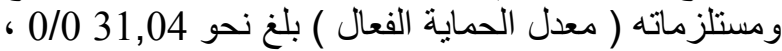

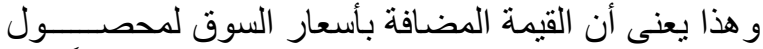

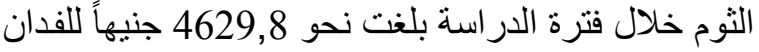

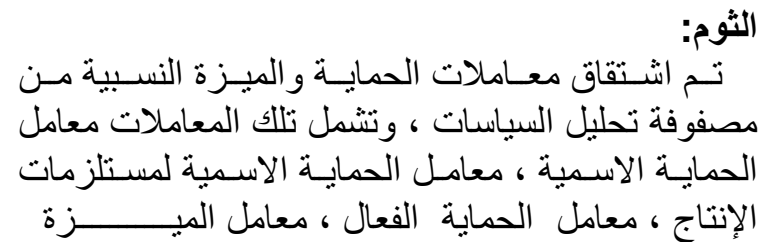

جدول رقم (2): مصفوفة تحليل السياسات لمحصول الثوم خلال الفترة ( 1994-2006).

\begin{tabular}{|c|c|c|c|c|c|c|c|c|c|}
\hline إنتاج القفاند & $\begin{array}{l}\text { سلكية } \\
\text { الاعمة } \\
\text { PPC }\end{array}$ & 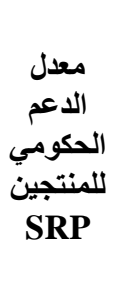 & المعلميزة & $\begin{array}{l}\text { الفمالية } \\
\text { EPR } \\
\text { EPعال }\end{array}$ & $\begin{array}{l}\text { الفماية } \\
\text { الفعال } \\
\text { EPC }\end{array}$ & 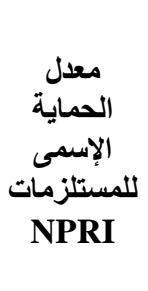 & $\begin{array}{l}\text { الإسماية } \\
\text { اللنواتج } \\
\text { NPRO }\end{array}$ & 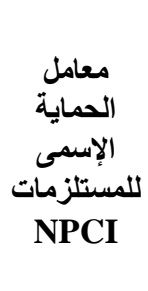 & $\begin{array}{l}\text { الاسماية } \\
\text { اللنواتجي } \\
\text { NPCO }\end{array}$ \\
\hline 1432,668 & 0,324 & 0,102 & 0,199 & 31,404- & 0,686 & 7,512- & 28,778- & 0,925 & 0,712 \\
\hline
\end{tabular}

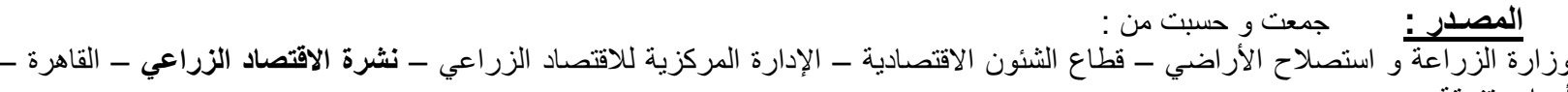

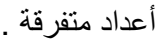

أى حو الى 68,6 0/0 من القيمة المضـافة بأسعار الحدود و

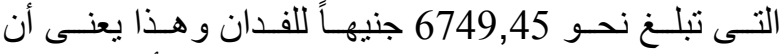

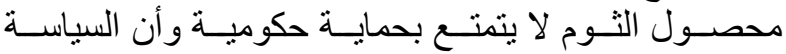

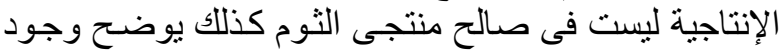
تشوهات سعرية في الأسواق المحلية الماتية

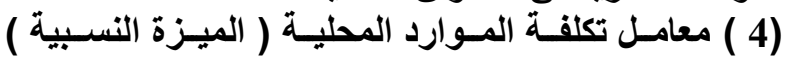

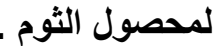
لقد تبين أن معامل تكلفة الموارد المحلية قد بلغ نحو

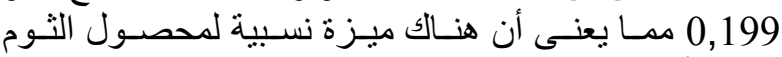

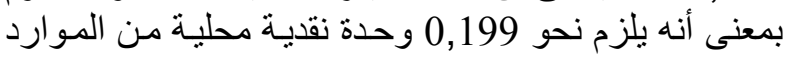

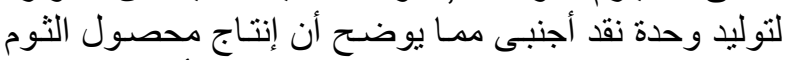

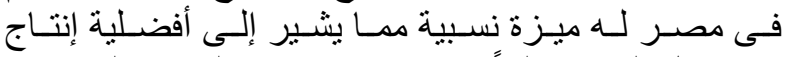

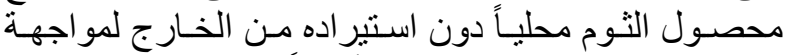

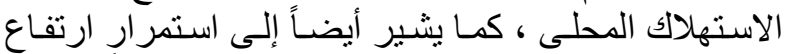

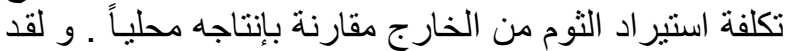

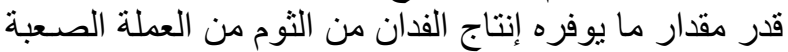

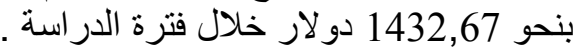

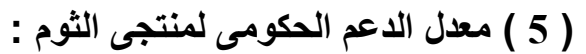

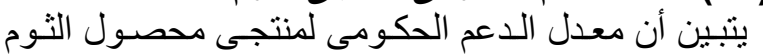

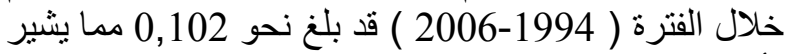
لأثر سياسة التحرر الاقتصادى على تكلفة مستلزمات الإنتاج ( الموارد المحلية). ( 6 ) معامل تكلفة سياسة الاعم .

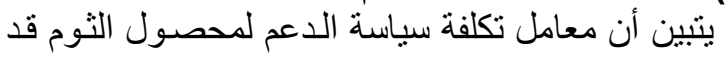

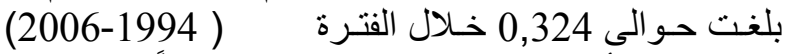

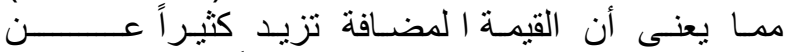

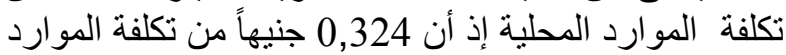

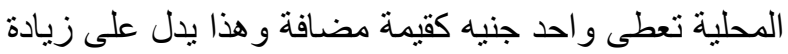

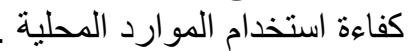

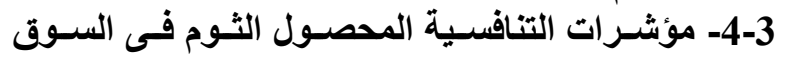
العالمى خلال الفترة (1994-2005 ). يتبين من بيانات الجدول رقم ( 3 ) ما يلي :

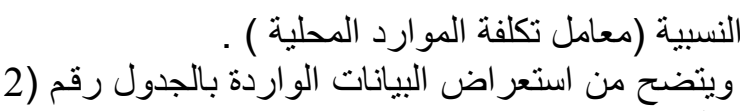

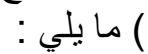

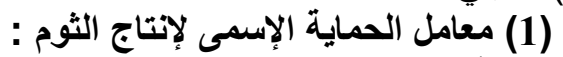

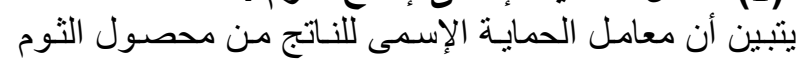

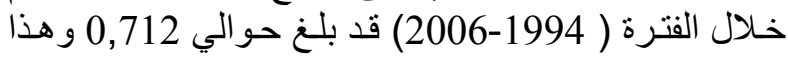

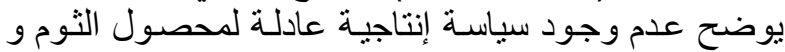

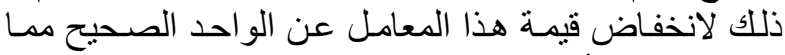
يعنى انخفاض أسعار الثوم المحلية المانية

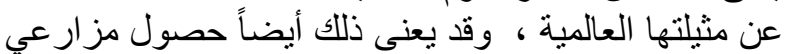

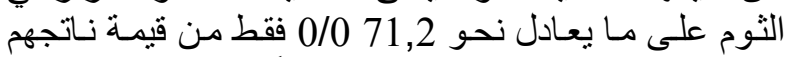

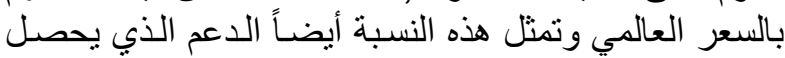
عليه المستهلكين لهذا المحصول.

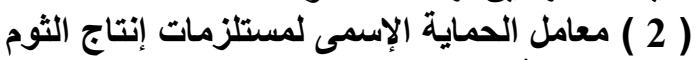

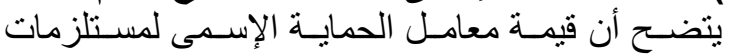

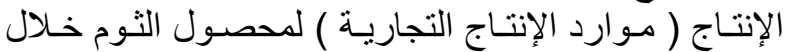

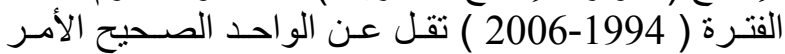

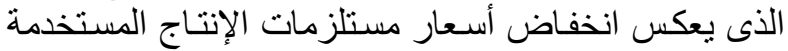

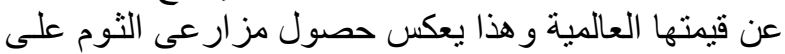

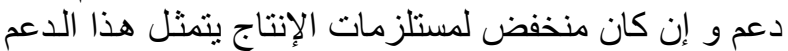

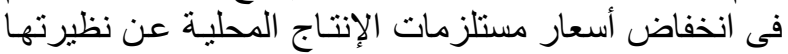

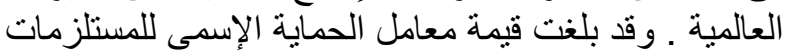

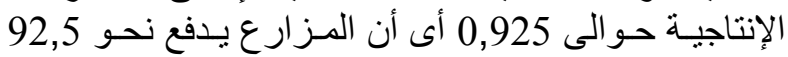

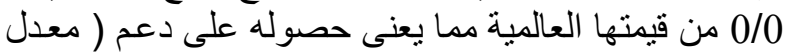

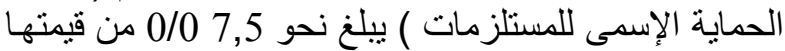

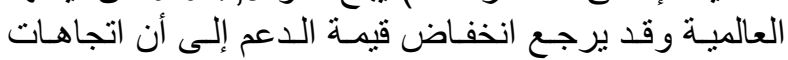

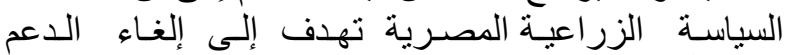

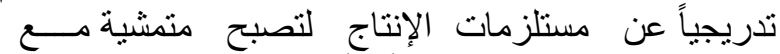

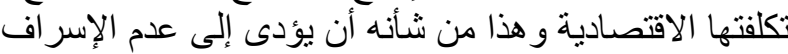

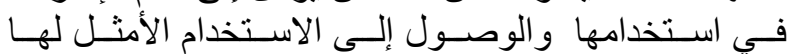
بالإضافة إلى تخفيف العبه على العيل ميز انية الدولة. ( 3 ) معامل الحماية الفعال لمحصول الثوم. 


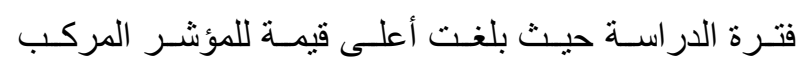

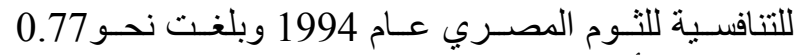

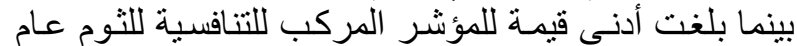

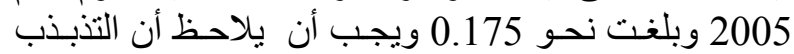
الو اضح للمؤشر المركب للتنافسية لمحصول الثوم المصري

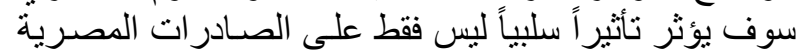

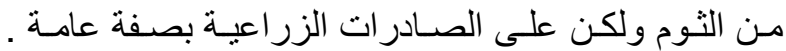

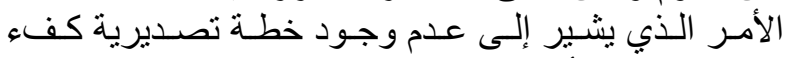

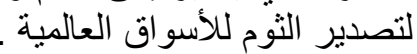

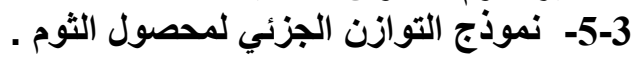

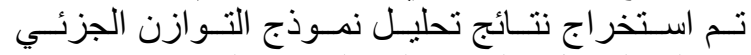

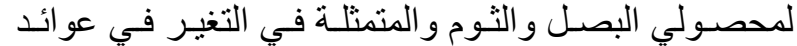
الحكومة والتغير في حصيلة النقد الأجنبي ومعدل التهلي التعريفة

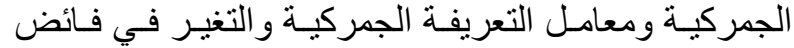

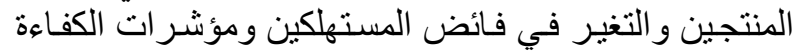
المتمثلة في العائد أو الخسارة الاجتماعية في الإنتاج و العائد

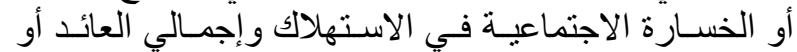

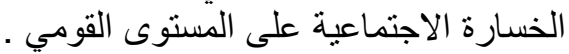

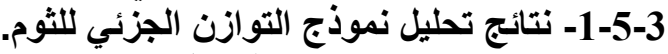

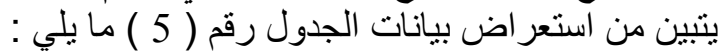
1- بزيـادة الـدعم الضـمني خـلانل عـامي 1997 و و 1999 على الترنيب بلغت عوة ائد الحكومسة حو الي

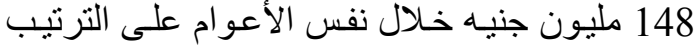

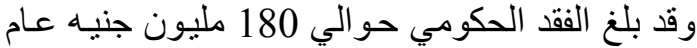
2006 كحد أقصسى ، في حين بلغت العو العو ائد أقصـاها

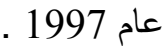

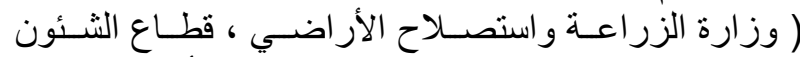

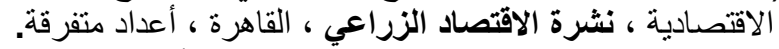

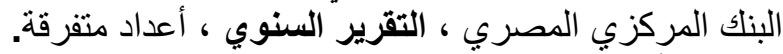

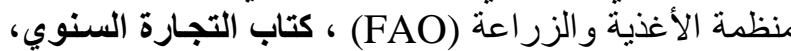

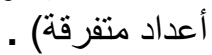

بمنوسط سنوي عن الفترة (1994 - 2006) بلغ حو الي 22

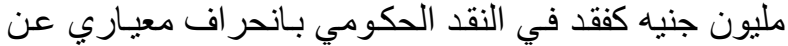
المتوسط بلغ حو الي 263 مليون جنيه .

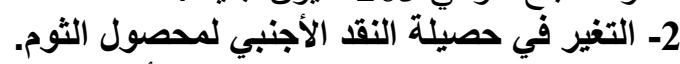

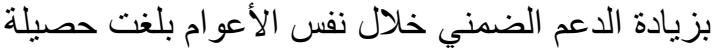

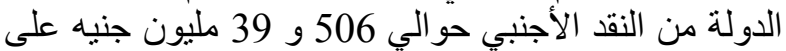
الترتيب ، وقد بلغت حصيلة النقد الأجنبي أدناهـا عـام 1999

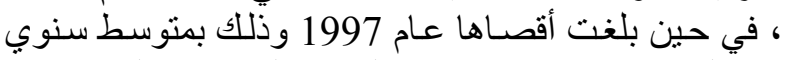
عن الفترة (1994 - 2006) بلـغ حوالي الفي 167 مليون جنيـه بانحر اف معياري عن المتوسط بلغ حو الي 152 مليون جنيه

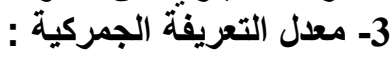

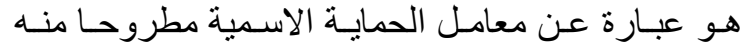

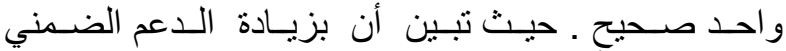

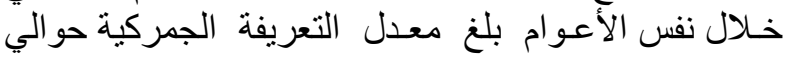

0,89و 0,46 على الترتيـب وقد بلــن معـدل التعريفـة

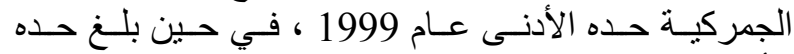

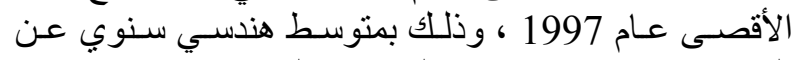

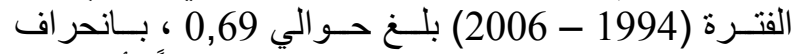

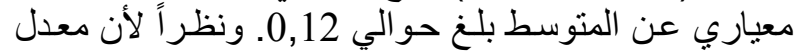

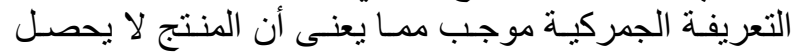

1- عدم وجود ميزة نسبية ظاهرية للثوم المصرى المصدر

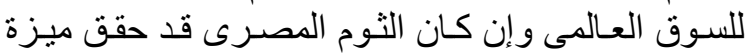

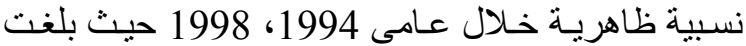

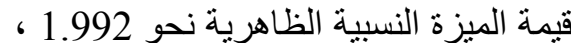

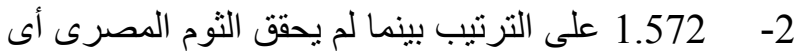
ميزة نسبية فى الأعو ام الأخرى .

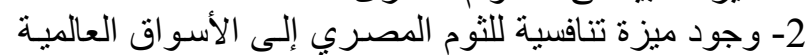

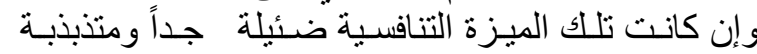
خلال الفترة ( 1994 - 2005 ) حيث بلغت فئت أعلى ميزة

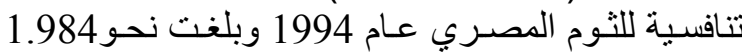

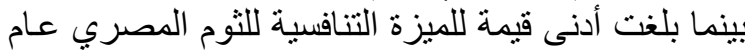
2000

السابقين إلى أن الثوم المصري يعتبر سلعة تصديرية

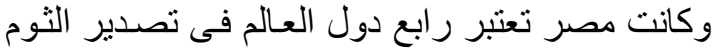

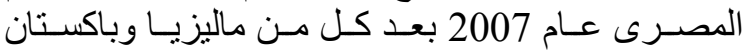

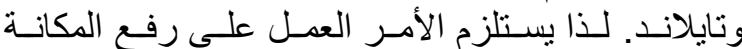

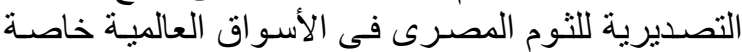

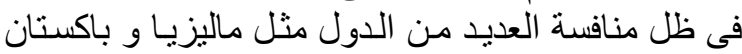

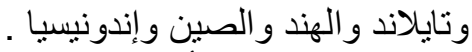

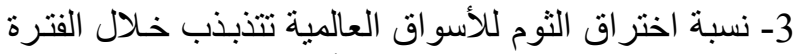

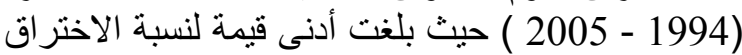

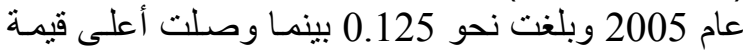
لها عام 1999 حيث بلغت نحس 0.862 وتنعتبر أسواق إيطاليا ونيوزيلندة و أير لندا و ألمانيا وفرنسا أهم أسو اق يته يتم

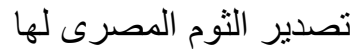

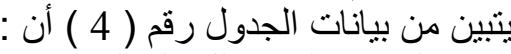
1- نسبة التكثيف النسبي للعمالة المستخدمة في إنتاج الثوم

\begin{tabular}{|c|c|c|c|}
\hline \multicolumn{2}{|c|}{ نسبة اختراق السوق } & التنافسية & السنة \\
\hline 0,236 & 1,984 & 1,992 & 1994 \\
\hline 0,635 & 0,647 & 0,649 & 1995 \\
\hline 0,539 & 0,854 & $\mathbf{0 , 8 5 5}$ & 1996 \\
\hline 0,425 & $\mathbf{0 , 8 2 1}$ & 0,822 & 1997 \\
\hline 0,526 & 1,569 & $\mathbf{1 , 5 7 2}$ & 1998 \\
\hline 0,862 & 0,343 & 0,343 & 1999 \\
\hline 0,526 & $\mathbf{0 , 1 7 7}$ & 0,186 & 2000 \\
\hline 0,714 & 0,179 & 0,192 & 2001 \\
\hline 0,812 & 0,236 & 0,273 & 2002 \\
\hline 0,536 & 0,700 & 0,716 & 2003 \\
\hline 0,458 & 0,409 & 0,415 & 2004 \\
\hline 0,125 & 0,249 & 0,265 & 2005 \\
\hline
\end{tabular}

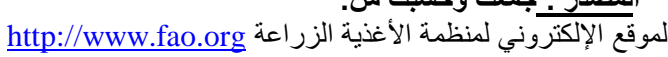

تتذبذب حول نفس المعدل خلال فترة الدر اسة حيث بلغت أعلى تكثيف لاستخدام العمالة عام 2000 وبلغ نحو 0.184

بينما بلغ أدنى تكثيف لاستخدام العمالـة عـام 1994 و بلـغ نحو 0.096

2- المؤشر المركب للتنافسية لمحصول الثوم المصري أخذ في التذبـب بين الارتفـاع والانخفـاض خـاضلافل الفترة ( 1994 -

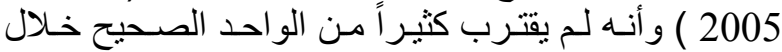


جدول رقم ( 4 ) : التكثيف النسبي للعمالة والمؤشر المركب

بزيـادة الــعم الضــنـي خـلال عـامي 1997 و 1999

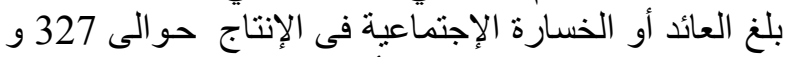

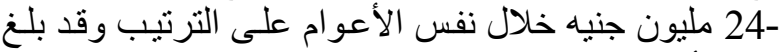

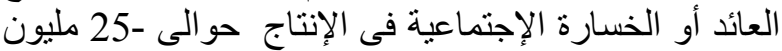

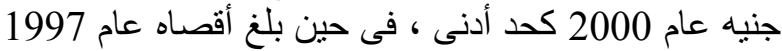

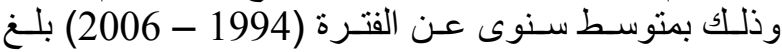

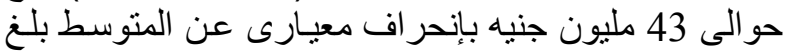

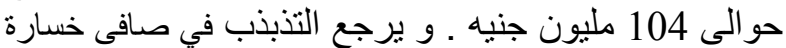

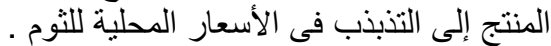

2-العائد أو الخسارة الإجتماعية فى الإستهلاك ل لمحصول الثوم.

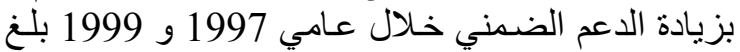

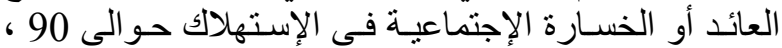

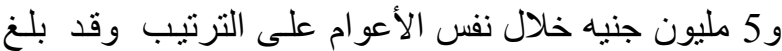

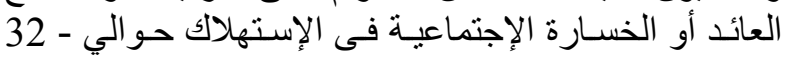

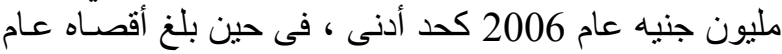
1997 وذللك بمتوسط سنوى عن الفترة (1994 - 1906 - 2006) بلغ حوالى - 7 مليون جنيه بإنحر اف معيارى عن المنيط المتوسط بلغ حو الى 31 مليون جنيه ـ ويرجيه بائحراف التذبذب في في التي صافى خسارة المستهلك إلى التذبذب في الأسـعار المحلية

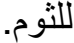

3- إجمالي العائد أو الخسارة الإجتماعية لمحصول الثوم.

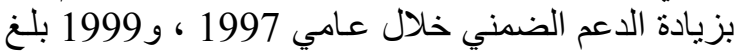

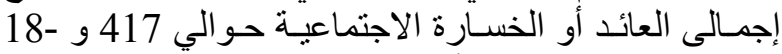

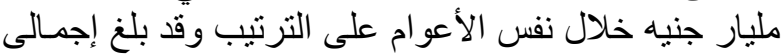

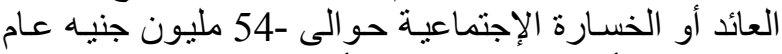

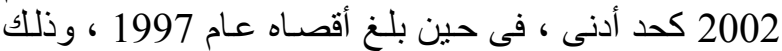

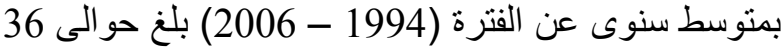
مليون جنيه بانحر اف معياري عن الفترة المتوسط بلغ حو الى 130

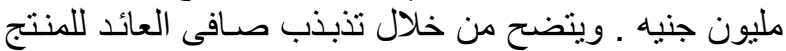

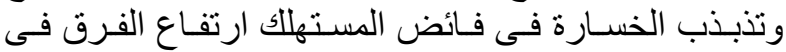

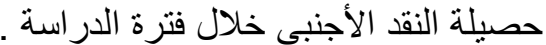

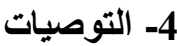

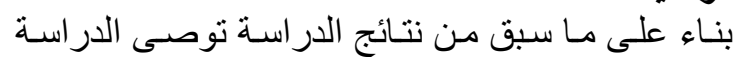

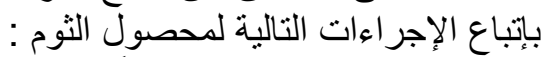

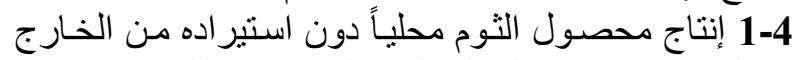

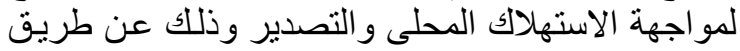
التوسع في الرقعة المنزر عة بالثوم في الأراضي الجديدة الجيدة

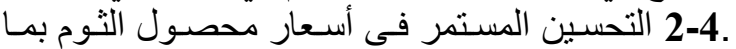
يتناسب مع الزيادة المستمرة فى التكاليف الإنتاجية
للتنافسية لمحصول الثوم خلال الفترة (1994-2005)

\begin{tabular}{|c|c|c|}
\hline للتنافسبة الموكب & اللتعثيفي & السنة \\
\hline $\mathbf{0 , 7 7 4}$ & 0,096 & 1994 \\
\hline 0,478 & 0,152 & 1995 \\
\hline 0,513 & 0,144 & 1996 \\
\hline 0,463 & 0,143 & 1997 \\
\hline 0,738 & 0,117 & 1998 \\
\hline 0,449 & 0,141 & 1999 \\
\hline 0,299 & 0,184 & 2000 \\
\hline 0,360 & 0,173 & 2001 \\
\hline 0,396 & 0,102 & 2002 \\
\hline 0,466 & 0,147 & 2003 \\
\hline 0,340 & 0,147 & 2004 \\
\hline $\mathbf{0 , 1 7 5}$ & 0,136 & 2005 \\
\hline
\end{tabular}

http://www.fao.org الموقع الإكتروني لمنظمة الأغذية الزر اعني

على دعم ضمني و لا توجد ضر ائب ضمنية يتحملها المنتج

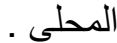
4- معامل التعريفة الجمركية .

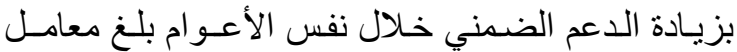

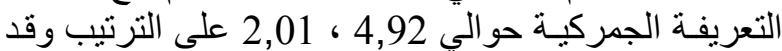

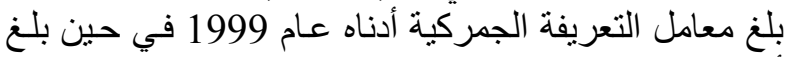
أقصاه عام 1997 ، وذلك بمنتوسط هندسي سنوي عن الفي الفترة

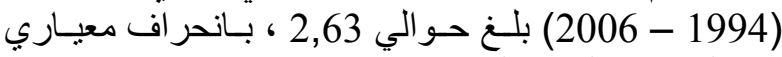
عن المتوسط بلغ حو الي 5- التغير في فائض المنتجين لمحصول الثئوم. بزيادة الدعم الضمني خـانلال عامي 1997 ، 157 ـ 1999

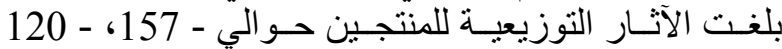

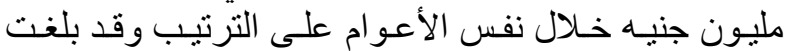

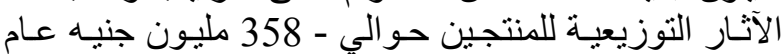

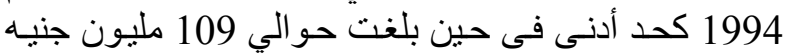

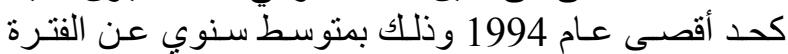

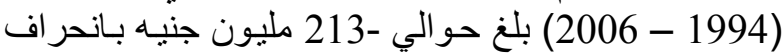
6عياري بلغ حوالي 86 مليار جنيه .

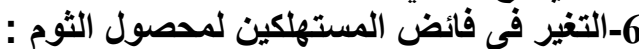

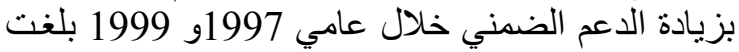
الآثار التوزيعية للمستهلكين حو الي 502 ، و و10 مليون جنيه التيه

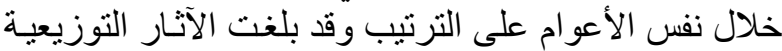

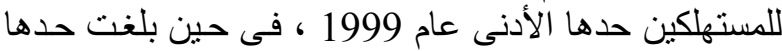

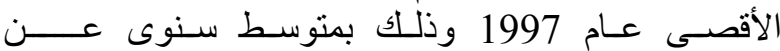

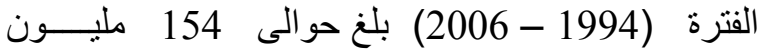

جنيه بإنحر اف معيارى بلغ حو الى 163 مليون جنيها .

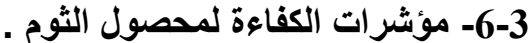

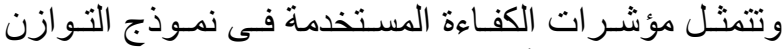

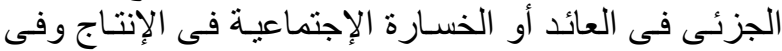

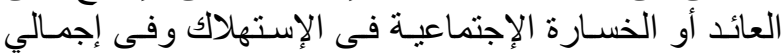

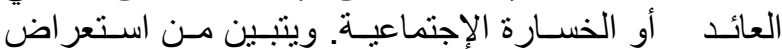

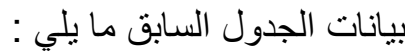

1- العائد أو الخسارة الإجتماعية فى الإنتاج ل لمحصول الثوم : 
W. M. EL-Bolony

جدول ( 5 ) : نتائج نموذج التوازن الجزئي لمحصول الثوم وأثره على التجارة الخارجية في جمهورية مصر العربية خلال الفترة 2006 - 2994

\begin{tabular}{|c|c|c|c|c|c|c|c|c|c|}
\hline \multirow[b]{2}{*}{ معامل التعريفة } & \multirow[b]{2}{*}{ الجعريفة } & \multirow[b]{2}{*}{ الأجرق في } & \multirow[b]{2}{*}{ العائد أو الفقد } & \multirow[b]{2}{*}{ للآلتآثار } & \multirow[b]{2}{*}{ للتمستهزيعين } & \multicolumn{3}{|c|}{ 两 } & \multirow[b]{2}{*}{ السنوات } \\
\hline & & & & & & الإجمالئي & الاجتماعسارة الأند & 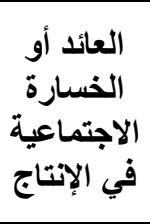 & \\
\hline 2,22 & 0,66 & 41 & 98- & 109- & 32 & $22-$ & 11- & 11- & 1994 \\
\hline 2,72 & 0,76 & 72 & 56- & 121- & 71 & 6- & 14- & 7 & 1995 \\
\hline 2,54 & 0,73 & 129 & 153- & 247- & 123 & $29-$ & $29-$ & 1 & 1996 \\
\hline 4,92 & 0,89 & 506 & 762 & $157-$ & 502 & 417 & 90 & 327 & 1997 \\
\hline 2,04 & 0,57 & 47 & 146- & 136- & 20 & $30-$ & 9- & 21- & 1998 \\
\hline 2,01 & 0,46 & 39 & $148-$ & 120- & 10- & 18- & 5 & 24- & 1999 \\
\hline 2,06 & 0,59 & 60 & $178-$ & 169- & 29 & $38-$ & 13- & $25-$ & 2000 \\
\hline 2,13 & 0,62 & 60 & $155-$ & 159- & 39 & $35-$ & 15- & $20-$ & 2001 \\
\hline 2,26 & 0,67 & 116 & 234- & 273- & 93 & 54- & 31- & 23- & 2002 \\
\hline 3,55 & 0,83 & 370 & 170 & $350-$ & 377 & 143 & $5-$ & 148 & 2003 \\
\hline 3,67 & 0,84 & 412 & 246 & 358- & 424 & 180 & 3 & 176 & 2004 \\
\hline 2,80 & 0,77 & 181 & $118-$ & 292- & 180 & 6- & $31-$ & 25 & 2005 \\
\hline 2,51 & 0,72 & 135 & 180- & 273- & 127 & 34- & $32-$ & 3- & 2006 \\
\hline 2,63 & 0,69 & 167 & $22-$ & 213- & 154 & 36 & $7-$ & 43 & المتوسط \\
\hline 0.82 & 0.12 & 152 & 263 & 86 & 163 & 130 & 31 & 104 & الانحر افياري \\
\hline
\end{tabular}

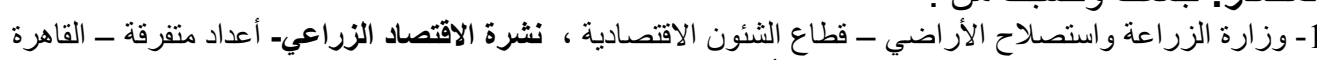

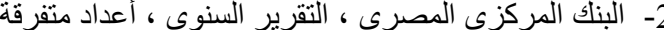

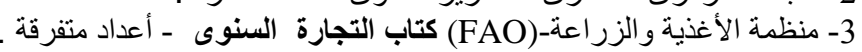




\section{الملاحق}

ملحق رقم (1) تطور المتغيرات الاقتصادية لمحصول الثوم خلال الفترة ( 1994-2006 )

\begin{tabular}{|c|c|c|c|c|c|c|c|c|}
\hline التكاليف للفدان بالجنيه & قيمة الصادرات & ألف طادرات & نسبة الاكتفاء & ألف طنهلاك & ألف طن & الإتتاجية & ألف فدانة & السنوات \\
\hline 112,599 & 9,0 & 6,25 & 106,34 & 98,59 & 104,84 & 8,81 & 11,9 & 1994 \\
\hline 105,324 & 4,0 & 2,86 & 102,46 & 116,36 & 119,22 & 8,946 & 13,33 & 1995 \\
\hline 110,069 & 9,0 & 7,17 & 102,89 & 248,44 & 255,61 & 10,07 & 25,38 & 1996 \\
\hline 106,093 & 13,0 & 3,7 & 102,38 & 155,48 & 159,18 & 9,567 & 16,64 & 1997 \\
\hline 105,014 & 4,0 & 3,16 & 101,85 & 170,47 & 173,63 & 9,641 & 18,01 & 1998 \\
\hline 104,243 & 3,0 & 2,92 & 101,32 & 221,3 & 224,22 & 8,802 & 25,47 & 1999 \\
\hline 104,843 & 3,0 & 3.51 & 101,33 & 263,16 & 266,67 & 8,945 & 29,81 & 2000 \\
\hline 106,324 & 4,0 & 4,29 & 102,03 & 211,22 & 215,51 & 9,737 & 22,13 & 2001 \\
\hline 104,686 & 6,0 & 3,05 & 101,63 & 187,02 & 190,07 & 9,213 & 20,63 & 2002 \\
\hline 110,721 & 21,0 & 7,14 & 103,56 & $7 ., 20$ & 207,84 & 9,18 & 22,64 & 2003 \\
\hline 106,614 & 14,0 & 4,27 & 102,33 & 183,64 & 187,91 & 9,453 & 19,88 & 2004 \\
\hline 111,578 & 18,0 & 7,03 & 104,53 & 155,1 & 162,13 & 9,528 & 17,02 & 2005 \\
\hline 113,218 & 18,0 & 8,01 & 105,19 & 154,16 & 162,17 & 9,53 & 17,02 & 2006 \\
\hline 107,794 & 9,0 & 4,87 & 102,91 & 182 & 187 & 9,34 & 19,99 & المتوسط \\
\hline
\end{tabular}

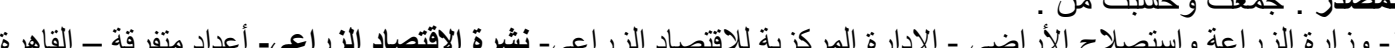

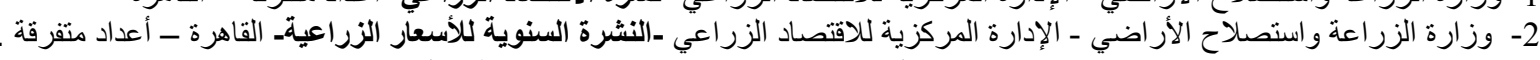

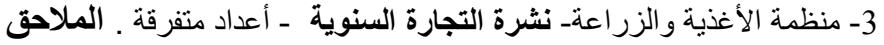




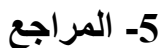

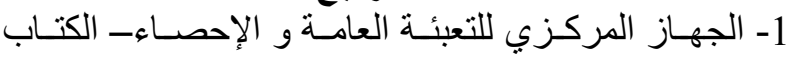

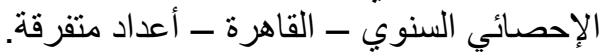

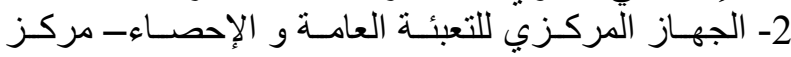

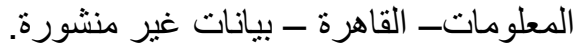

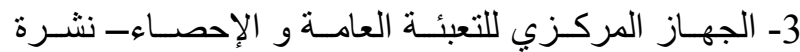

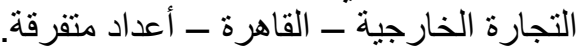

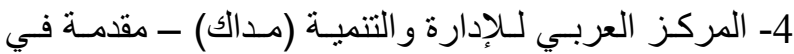

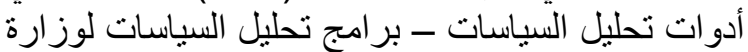

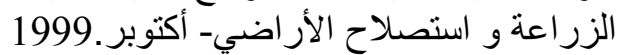

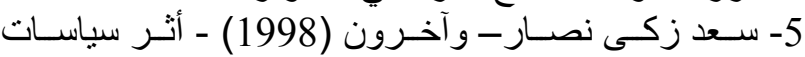

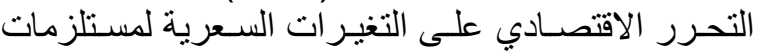

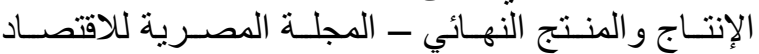
الزراعي - مجلد 8 - عدد 1 - مارس .1998

6- منظمة الأغذية و الزراعة (FAO)

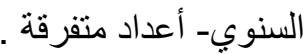

7- وزارة الزر اعـة و استصـلاح الأر اضـي ـ قطـاع الثـئون

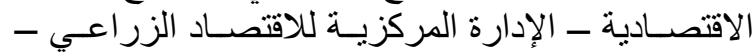

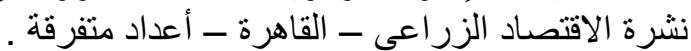

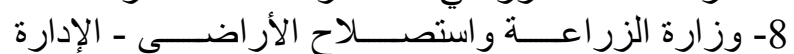

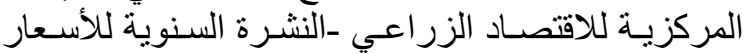

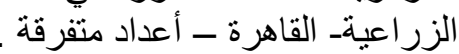

الزراعية وتحقيق صـافى عائد مجزى يفوق صـافى العائد

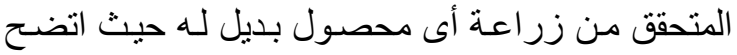

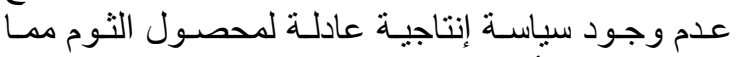
يعنى انخفاض أسعاره المحلية عن مثيلتها العالمية .

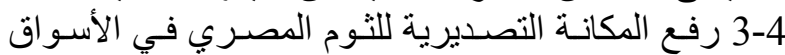

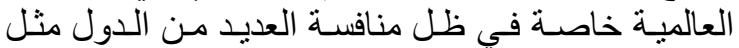

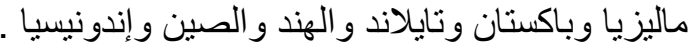

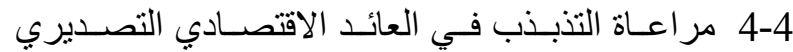

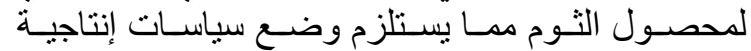

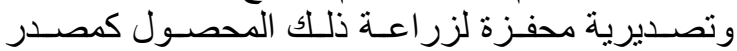

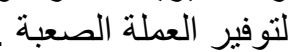

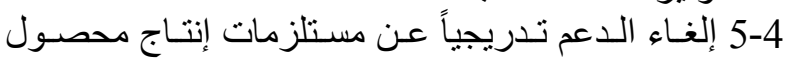

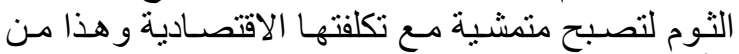

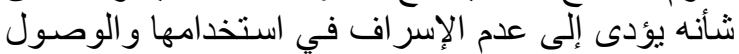

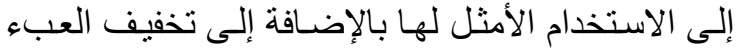

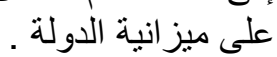

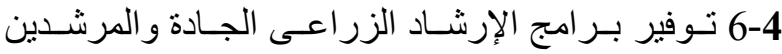

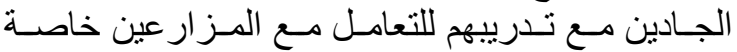

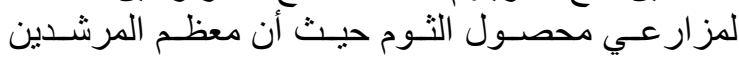

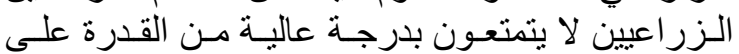

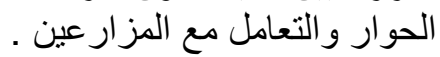

